\title{
Inserção do professor de educação física no programa de ensino integral
}

\author{
Insertion of physical education teacher in the programa de ensino integral \\ Inserción de profesor de educación física en el programa de ensino integral \\ GuIlHerme Augusto da Silva ${ }^{1}$; MÁrio LuCio de AMORIM Filho²; \\ GLAUCO NUNES SOUTO RAMOS ${ }^{3}$ \\ Universidade Federal de São Carlos, UFSCAR, São Carlos-SP, BraSil \\ Secretaria da Educação do Estado de São Paulo, SEE-SP, São Carlos-SP, Brasil
}

RESUMO

O Programa de Ensino Integral (PEI) possui a proposta de aumentar a carga horária e alterar a matriz curricular das escolas fundamentadas pela Base Nacional Comum Curricular, acrescentando atividades além das aulas regulares. O artigo tem o objetivo de analisar a inserção profissional de um professor de Educação Física no PEI. Foi realizado um estudo de caso com abordagem qualitativa, através de uma entrevista estruturada com o professor. A partir disso, foram evidenciadas as temáticas relacionadas à trajetória profissional do professor, à inserção docente ao PEI e aos aspectos positivos e negativos do Programa. Com isso, percebeu-se que tanto a proposta em si quanto a parte diversificada do PEI são consideradas boas, porém, as atribuições específicas ao professor são excessivas e conseguiriam ser amenizadas com a contratação de mais professores no Programa. Sugere-se novos estudos com mais professores de Educação Física e outros atores educacionais.

Palavras-chave: Educação Física Escolar. Inserção Profissional. Estudo de Caso.

\begin{abstract}
The Programa de Educação Integral (PEI) has the purpose of increasing the classess time and change the education content of schools based on the Base Nacional Comum Curricular, by adding extra activities to regular classes. This paper aims to analyze the experience lived by a teacher of physical education in PEI. A case study was carried out with a qualitative approach, by a structured interview with the teacher. From this study, it was highlighted the themes related to the teacher's professional trajectory, the teacher's insertion to this program and its positive and negative aspects. In this way, it was concluded that both the proposal and the diversified aspect of PEI are considered good, however, specific attributions to the teacher are excessive and could be softened by hiring more teachers for this program. Further studies with more teachers of physical education and other educational actors are suggested.
\end{abstract}

Keywords: School Physical Education. Professional Insertion. Case Study.

\section{RESUMEN}

El Programa de Educação Integral (PEI) tiene el propósito de aumentar el tiempo de clases y cambiar el contenido educativo de las escuelas en la Base Nacional Comum Curricular, agregando actividades extra a las clases regulares. Este trabajo tiene como objetivo analizar la experiencia vivida por un docente de educación física en el PEI. Se realizó un estudio de caso con enfoque cualitativo, mediante entrevista estructurada con el docente. De este estudio se destacaron los temas relacionados con la trayectoria profesional del docente, la inserción del docente en el programa y sus aspectos positivos y negativos. De esta manera, se concluyó que tanto la propuesta como el aspecto diversificado del PEI se consideran buenos, sin embargo, las atribuciones específicas al docente son excesivas y podrían suavizarse contratando más docentes para este programa. Se sugieren más estudios con más profesores de educación física y otros actores educativos.

Palabras clave: Educación Física Escolar. Inserción Profesional. Estudio de Caso.

1 Graduando em Educação Física pela UFSCar. E-mail: guilhermeas@estudante.ufscar.br. ORCID: http://orcid.org/0000-0002-3988-5921.

Professor de Educação Física da SEE-SP. E-mail: marioamorimmusic@gmail.com. ORCID: http://orcid.org/0000-0002-5301-8808.

${ }^{3}$ Professor Associado do Departamento de Educação Física e Motricidade Humana da UFSCar e do Programa de Mestrado Profissional em Educação Física em Rede Nacional (PROEF/UFSCar). E-mail: glauco@ufscar.br. ORCID: http://orcid.org/0000-0003-2644-2838. 


\section{INTRODUÇÃO}

A educação vem sendo objeto de estudo de vários pesquisadores interessados em melhorar a qualidade de ensino das escolas brasileiras. Cada contexto escolar apresenta uma realidade específica, que influencia e demonstra a complexidade de desenvolver um trabalho pedagógico que envolva as demandas de alunos e professores. Há uma busca para tentar solucionar problemas da educação brasileira, a qual se torna dificultada pelas diversas variáveis envolvidas, e o resultado desse processo de ensino reflete na formação do cidadão.

No ano de 2012, uma das alternativas criadas pela Secretaria da Educação do Estado de São Paulo (SEE-SP) em busca de qualidade de ensino foi o modelo de escola chamado Programa de Ensino Integral - PEI (SÃO PAULO, 2012a). O PEI foi estabelecido pela Lei complementar $\mathrm{n}^{\circ} 1.164$, de 04 de janeiro de 2012, sendo alterado pela Lei complementar $\mathrm{n}^{\circ}$ 1.191, de 28 de dezembro de 2012 (SÃO PAULO, 2012b; 2012c).

O PEI atua nos anos finais do ensino fundamental $\left(6^{\circ}\right.$ ao $9^{\circ}$ ano) e no ensino médio $\left(1^{\mathrm{a}}\right.$ à $3^{\mathrm{a}}$ série) (SÃO PAULO, 2012a) e procura estabelecer uma relação de integração entre a Base Nacional Comum Curricular (BNCC) (BRASIL, 2017), que continua na matriz curricular da escola, com a parte diversificada específica do Programa. Além do aumento da carga horária, estas escolas têm o objetivo de explorar a jornada com ações para estimular os educandos a aprender, de maneira globalizada, as diversas capacidades para o exercício da cidadania (SÃO PAULO, 2012a).

Em 2014, o governo brasileiro aprovou a criação do Plano Nacional de Educação (PNE), com a finalidade de elaborar estratégias, diretrizes e metas na política educacional, buscando melhorar a qualidade de ensino das escolas brasileiras até o ano de 2024 (BRASIL, 2014). Dentro das 20 metas estabelecidas pelo PNE, destaca-se para esta pesquisa a meta $n^{\circ} 6$ : "[...] oferecer educação em tempo integral em, no mínimo, 50\% das escolas públicas, de forma a atender, pelo menos, 25\% dos(as) alunos(as) da educação básica" (BRASIL, 2014, p. $6)$.

O Relatório do $3^{\circ}$ ciclo de monitoramento das metas do Plano Nacional de Educação 2020 vai de encontro à meta $n^{\circ} 06$ do PNE, apresentando dados que demonstram o declínio do percentual de escolas que possuem ensino em tempo integral no período de 2014 a 2019, não atingindo o atendimento de $25 \%$ dos alunos da educação básica (BRASIL, 2020). O mesmo relatório considera urgente que o Brasil reverta essa situação para conseguir alcançar uma educação de excelência equiparada às nações desenvolvidas, que já apresentam educação em tempo integral de maneira expressiva (BRASIL, 2020).

O modelo pedagógico do PEI é orientado por quatro princípios fundamentais que regem a unidade escolar e servem para alcançar seu objetivo de formar jovens autônomos, solidários e competentes, sendo eles: a Educação Interdimensional, a Pedagogia da Presença, os 4 Pilares da Educação para o Século XXI e o Protagonismo Juvenil. O princípio que possui maior destaque é o Protagonismo Juvenil, que se concretiza no contexto escolar com o desenvolvimento das atividades propostas, como: "Líderes de Turma, Clubes Juvenis e o Projeto de Vida" (SÃO PAULO, 2012a).

O Projeto de Vida é um documento proposto pelo PEI, em que os professores e gestores fornecem subsídios para os alunos construírem um projeto com ações para alcançar os seus objetivos. As ações pedagógicas da escola devem ser estabelecidas com foco neste documento, que é um dos objetivos finais do Programa em questão (SÃO PAULO, 2012a).

De acordo com o PEI, no ensino fundamental (anos finais) existe ênfase maior na autonomia do aluno em relação à tomada de decisão, valorizando a continuidade dos estudos, em virtude do seu Projeto de Vida. No ensino médio, o aluno tem as opções de preparação para o ensino superior com aulas de Preparação Acadêmica e para o mercado de trabalho, com aulas de Introdução ao Mundo do Trabalho. Em ambos os níveis de ensino, existe uma 
preocupação com os aspectos técnicos para a elaboração do seu Projeto de Vida (SÃO PAULO, 2012a).

Nas disciplinas regulares, o Programa segue como referência o Currículo do Estado de São Paulo vigente, estipulando como objetivo de aprendizagem as habilidades e competências definidas por cada série e estabelecendo estratégias para melhorar o rendimento do aluno (SÃO PAULO, 2012a).

Os docentes e demais educadores do PEI têm obrigatoriamente dedicação única para unidade escolar que atuam: "Dedicação Plena e Integral que estabelece a atuação dos profissionais por 40 horas semanais" (SÃO PAULO, 2012a, p. 12). Com isso, o Programa acredita fortalecer as relações interpessoais com todos os envolvidos no processo de ensino e de aprendizagem, com a finalidade de promover a integração.

A proposta de trabalho para o docente que deseja lecionar nesse Programa parte do princípio da presença contínua em diversos momentos do período de funcionamento da escola passando por todas as atividades previstas pelo PEI, desde as disciplinas regulares do Currículo do Estado de São Paulo até outras atividades presentes na matriz curricular: Clubes Juvenis, elaboração do Projeto de Vida, plano de nivelamento, disciplinas eletivas e orientação de estudo. O nível de interferência dos professores muda em relação a cada atividade, devido à proposta de cada uma delas, entretanto, além das disciplinas regulares, o professor deve fornecer apoio em todas essas atividades.

A atuação do professor no PEI torna-se integralizada e diversificada. Ocorre desde uma atuação individual como suporte para orientação de alunos para criação do Projeto de Vida, elaboração de estratégias para realização do Nivelamento, Orientação de Estudo até o auxílio na construção dos Clubes Juvenis:

Das atribuições dos professores dessas escolas, destacam-se: i) elaboração programa de ação, com indicadores e metas relacionadas à sua atuação; ii) produção de materiais didáticos; iii) substituição de aulas dos demais professores; iv) elaboração de plano bimestral e guias de aprendizagem de suas respectivas disciplinas; v) atuação na parte diversificada do currículo, que inclui disciplinas eletivas e orientação aos alunos em seus respectivos projetos de vida; e vi) tutoria aos alunos (SÃO PAULO, 2014a, p. 6).

No PEI o professor é avaliado a partir da Avaliação $360^{\circ}$. Ela é realizada por várias pessoas envolvidas na instituição escolar, consideradas aptas para julgar a atuação do profissional valorizando as diferentes perspectivas definidas pelas diversas ocupações dentro da escola. No caso específico do docente, ocorre a avaliação das suas funções por parte dos alunos, dos demais docentes, professores coordenadores de área e coordenador geral (SÃO PAULO, 2014a).

A partir das avaliações dos docentes, surge o fornecimento de suporte para uma formação continuada, com objetivo de aprimorar seu desempenho (SÃO PAULO, 2012a). Devido a essas condições de trabalho explanadas, o Programa prevê "Gratificação de Dedicação Plena e Integral - GDPI, que corresponde a 75\% do respectivo salário-base" (SÃO PAULO, 2014a, p. 9), para os professores atuantes em virtude da sua dedicação restrita e integral à unidade escolar e ao Programa.

Com base neste recorte inicial, especificamente ao darmos destaque ao componente curricular Educação Física, podemos sinalizar que a trajetória dessa área de conhecimento foi historicamente marcada por mudanças de paradigmas que influenciam até hoje em muitas práticas docentes (BORGES, 2001). A Educação Física é diferenciada em relação aos demais componentes curriculares, em virtude da sua área do saber e características pedagógicas englobarem as práticas corporais e outros espaços de atuação, além das salas de aula, como 
quadras e pátios da escola. Em alguns casos, estes atributos constroem nos professores e alunos, interpretações equivocadas sobre a Educação Física (SOUZA; PAIXÃO, 2015).

Para compreender a profissão docente do professor de Educação Física, é necessário entender o que é ser professor no Brasil. Reali e Reyes (2009) definem que a atividade do professor engloba as responsabilidades sociais e políticas dentro da escola e da comunidade, portanto, ser professor é ir além dos conteúdos curriculares da sua área de atuação para realizar as inúmeras ocupações da profissão docente, complexa e diversificada (REALI; REYES, 2009).

O professor iniciante pode deparar-se com algumas dificuldades no contexto escolar. De acordo com Papi e Martins (2010), os conhecimentos adquiridos ao longo de sua formação serão observados, analisados e testados, concebendo ao professor o caminho de assumir uma postura inovadora perante a realidade apresentada, ou de reprodução de atuações pouco reflexivas (PAPI; MARTINS, 2010).

$\mathrm{Na}$ literatura encontram-se definições de professor iniciante, a partir da inserção na carreira e do tempo de docência. De acordo com Pacheco e Flores (1999) o período de até um ano de atuação como docente, pode definir o professor como sendo iniciante. Em estudo com dois professores de Educação Física, Amorim Filho e Ramos (2010), consideraram o professor novato àquele que estava há um ano e meio na docência. Já nos estudos de Reali, Tancredi e Mizukami (2010) e Cericato (2017) encontramos um período mais longo, de até cinco anos de atuação como docente, para ser definido como iniciante.

Para além do tempo da docência, entendemos que a cada desafio e/ou mudança de escola, proposta pedagógica ou programa institucional - como o próprio PEI -, o professor (mais ou menos experiente) passa por novos processos de adaptação e consolidação profissional e, nestes casos, podemos chamar de "iniciante" em relação ao novo desafio. Nas palavras de Silva e Cruz (2020):

\footnotetext{
Depreende-se que a dimensão temporal ganha relevância nos estudos que configuram a carreira docente. Contudo, questiona-se se, além do tempo de carreira, há outros fatores que se relacionam ao trabalho de modo a garantir a consolidação do desenvolvimento e da profissionalização docente, alinhando princípios que norteiem o reconhecimento das especificidades do exercício do magistério e as condições reais e objetivas daqueles que realizam o seu trabalho (p. 441).
}

Obviamente, sem desconsiderar sua trajetória e tempo de docência o que, muito provavelmente, contribuirá para esse novo contexto e desafio docente. Como veremos mais à frente, este é o caso do sujeito de nossa pesquisa.

O Anuário Brasileiro da Educação Básica de 2019 defende que formar docentes qualificados faz parte de uma das medidas mais importantes para garantir uma educação de qualidade (CRUZ; MONTEIRO, 2019). Na formação de professores, alguns aspectos históricos podem ser transmitidos por gerações e influenciar o modo de exercer a docência.

Nas primeiras décadas do século XX, a Educação Física teve grande fundamentação nas ciências biológicas, que proporcionaram embasamento científico para a área, assegurando sua presença nas escolas, os quais continham instrutores físicos do exército, prevalecendo a metodologia militar, ainda refletida no ensino da Educação Física (SOARES et al., 1992; BORGES, 2001).

Contudo, em meados da década de 1980 houve o chamado movimento renovador da Educação Física brasileira que trouxe para a área, com base nas ciências humanas, novas perspectivas pedagógicas (BRACHT, 2010). A partir daí, vinculada às questões culturais, entendemos a Educação Física na escola como um componente curricular que ensina conhecimentos e saberes da cultura corporal de movimento. Isto é, as formas culturais que são 
historicamente construídas e explicitadas por meio dos jogos, dos esportes, das ginásticas, das atividades rítmicas/expressivas, das danças e das lutas/artes marciais (BETTI, 2001).

Para além da diversidade das manifestações, estes conhecimentos e saberes da cultura corporal de movimento, de acordo com Bracht (1999; 2010), precisam articular o fazer corporal e o saber sobre este fazer, entendendo, deste modo, que os conteúdos das aulas de Educação Física “[...] devem ser tematizados de forma historicizada, para que fique claro para alunos que essas formas de movimento são construções socioculturais que abrigam significados datados" (BRACHT, 2010, p. 3).

Neste sentido, o docente de Educação Física que começa a lecionar no PEI, em particular, deve enfrentar essas dificuldades comumente características pela trajetória da área e se adaptar às novas concepções de ensino presentes no Programa. Por este motivo, o objetivo deste estudo foi analisar a inserção profissional de um professor de Educação Física no PEI, em uma escola do interior do estado de São Paulo.

\section{Processo Metodológico}

A abordagem dessa pesquisa segue por um viés qualitativo que, em acordo com Negrine (2010), indica que este tipo de abordagem possui como embasamento científico a manipulação das informações adquiridas, descrevendo e analisando-as para, posteriormente, buscar interpretar e refletir a partir de referenciais teóricos.

O estudo delimita um caso específico, sobre um único professor de Educação Física no PEI em uma escola na cidade de São Carlos-SP, caracterizando o estudo de caso qualitativo (LÜDKE; ANDRÉ, 1986). A cidade de São Carlos localiza-se no interior do estado de São Paulo, estima-se que a sua população consista em 254.484 pessoas (IBGE, 2020). De acordo com os dados abertos da educação, apresentado pelo site da Secretaria de Educação do Estado de São Paulo (SÃO PAULO, 2020), a cidade de São Carlos consta com cinco escolas participantes do PEI. A escola da rede pública estadual participante do estudo está localizada na região central do município em questão.

Para este estudo foi realizada uma entrevista estruturada que contou com um roteiro composto por onze questões abertas. Segundo Negrine (2010), a entrevista somente pode acontecer quando o sujeito que será entrevistado estiver frente a frente com o entrevistador estabelecendo uma relação de conversa, com a finalidade de adquirir informações. A entrevista estruturada é quando "[...] o investigador segue a ordem estabelecida das perguntas e um conjunto específico de procedimentos" (NEGRINE, 2010, p. 75-76).

Antes da entrevista, foi realizado o contato com o professor para saber sobre a sua disponibilidade em responder os possíveis questionamentos que poderiam surgir decorrentes da pesquisa. A entrevista aconteceu no dia 23 de setembro de 2019, às 08 horas da manhã na escola onde o entrevistado leciona. A gravação durou 40 minutos e 45 segundos, com perguntas que tiveram a finalidade de extrair informações sobre a trajetória profissional do professor de Educação Física entrevistado e a sua inserção no PEI.

Para realizar a entrevista, o professor assinou o Termo de Consentimento Livre e Esclarecido (TCLE), que consta desde o objetivo do estudo até os riscos que poderiam surgir decorrentes da pesquisa. As informações foram capturadas através do gravador de áudio do celular LG K10 Power e transcritas para, posteriormente, realizar a análise dos dados. 


\title{
ANALISANDO A INSERÇÃo dO PROFESSOR DE EdUCAÇÃo FíSICA NO PEI
}

Os dados foram analisados e categorizados, conforme proposto por Gomes (2004). Este tipo de análise consiste em encontrar elementos em comum e agrupá-los em categorias. Desta forma, foram criadas categorias de análise, que tratam das questões relacionadas à trajetória profissional do professor de Educação Física, à inserção docente ao Programa e aos aspectos positivos e negativos do PEI. Neste momento procuramos relacionar as categorias criadas com a fundamentação teórica, com a finalidade de aprofundar e construir novos conhecimentos.

Mediante as informações contidas no TCLE, a fim de preservar a identidade dos envolvidos, alteramos os nomes que apareceram na entrevista: o professor participante da pesquisa será identificado como João; a escola, da cidade de São Carlos integrante do PEI, em que João leciona, será identificada como E.E. Maldonado e outras escolas citadas durante a entrevista serão identificadas como X.

O professor João licenciou-se em Educação Física pela Universidade Federal de São Carlos em 2007; trabalhou como professor substituto/eventual do município por dois bimestres e, em 2010, foi aprovado em concurso público do estado de São Paulo. Assumiu seu cargo em 2011, quando começa a exercer sua profissão como professor efetivo, ou seja, de acordo com Amorim Filho e Ramos (2010), Reali, Tancredi e Mizukami (2010) e Cericato (2017) não podemos considerá-lo como iniciante na docência, pois o professor possui uma carreira de mais de cinco anos de atuação como professor de Educação Física, entretanto, em 2019 era seu primeiro ano lecionando em uma escola participante do PEI. Em suas palavras:

\begin{abstract}
Eu acho que assim, no início quando a gente se insere numa escola PEI igual foi no meu caso teve um trauma de realidade [...]. Aqui na escola PEI sou responsável por diversos setores diferentes, pouco diferente das escolas regulares onde você fica específico dentro da sua área de formação, a Educação Física, e aqui na PEI, [...] eu sou responsável, por diversos setores que tem dentro da instituição aqui de ensino, então foi um pouco um choque inicial, né? Mas conforme a gente vai trabalhando a gente vai se adequando um pouquinho ao programa, a gente vai aprendendo um pouquinho sobre o programa. Eu ainda estou na fase inicial, aqui há um pouco mais de um semestre, na escola, mas já é uma aprendizagem gigantesca já, eu acho que nos próximos anos aí vou estar assim bem inteirado mesmo na totalidade do programa (JOÃO).
\end{abstract}

Como vimos, o Programa possui algumas características específicas em sua matriz curricular diferenciando-o das escolas de ensino regular. Logo, surgem alguns desafios e dificuldades decorrentes desse contexto escolar. Considerando o tempo de atuação do professor no Programa podemos dizer que João é um professor iniciante no PEI, no sentido de conhecer a proposta pedagógica e de enfrentar os desafios.

No período de iniciação profissional, de acordo com Papi e Martins (2010), o professor se depara com a realidade que irá testar os seus conhecimentos adquiridos ao longo da sua vida. No contexto escolar, a sua postura e suas ações pedagógicas serão observadas, analisadas e testadas, concebendo ao professor o caminho de assumir uma postura inovadora perante a realidade apresentada, ou de reprodução de atuações pouco reflexivas (PAPI; MARTINS, 2010).

$\mathrm{Na}$ entrevista realizada ficou evidente que apesar de João não ser mais considerado um professor iniciante na docência pela literatura, no PEI, o caso é diferente. O professor demonstrou que teve algumas dificuldades nessa mudança de contexto, devido às diferentes responsabilidades atribuídas aos professores pertencentes ao Programa e à falta do treinamento previsto que, infelizmente, não ocorreu como será apresentado mais à frente. 
O Programa foi criado em 2012 pela SEE-SP e a escola E.E. Maldonado aderiu ao Programa no ano de 2014 (SÃO PAULO, 2020). Ao longo do período de criação e adesão do PEI na escola até o momento de inserção do professor ao Programa, em 2019, João teve conhecimento do Programa através do contato com outras pessoas que trabalharam no PEI. De acordo com a entrevista, o conhecimento que o professor tinha não contemplava toda a complexidade do Programa, com isso a responsável pela divulgação desta oportunidade para o professor foi a supervisora de ensino da escola onde João lecionava antes do PEI.

No site da Diretoria de Ensino (DE) de São Carlos, podemos encontrar o edital de credenciamento de 2018, para a atuação em 2019, como professor titular no PEI (SÃO PAULO, 2018). Para participar do processo seletivo do PEI, de acordo com o edital, o professor deve possuir licenciatura plena, estar ciente do Regime de Dedicação integral, ser voluntário para pertencer ao Programa e, para finalizar, deve possuir, no mínimo, três anos de experiência como docente na rede pública estadual.

A seleção aconteceu a partir de alguns requisitos definidos pelo edital para identificar e classificar as competências do professor necessárias para atuar no PEI. O edital prevê uma análise do perfil do professor, através do seu histórico e uma entrevista presencial na qual, “[...] será avaliado o perfil do profissional para atuação no modelo pedagógico das Escolas Estaduais do Programa Ensino Integral, mediante avaliação por competência" (SÃO PAULO, 2018, p. 1).

Após passar por esse processo seletivo, que inclui desde a entrega de documentações, pré-avaliação e a realização de uma entrevista, João conseguiu ser selecionado para atuar no Programa de Ensino Integral. O professor apresentou rendimentos satisfatórios para os avaliadores, conquistando o direito de escolher em qual escola gostaria de lecionar.

Os momentos como professor iniciante na escola E.E. Maldonado apresentaram mudanças significativas em sua vida profissional, no qual foi denominado por João como sendo um "trauma de realidade". As responsabilidades atribuídas ao professor são os conteúdos previstos na BNCC, e as partes diversificadas da matriz curricular do Programa (SÃO PAULO, 2014a). Está previsto como função do professor criar o programa de ação com "[...] indicadores e metas relacionadas à sua atuação" (SÃO PAULO, 2014a, p. 6). João menciona, na entrevista, que esse programa de ação é realizado semestralmente para cada disciplina, desde as específicas do PEI, como as disciplinas referentes à BNCC.

Após sua inserção, o professor teve que trabalhar, principalmente, a partir do princípio do "Protagonismo Juvenil", pois é assumido pelo Programa que é o princípio que deve possuir destaque (SÃO PAULO, 2012a). Com isso, é determinado que a atuação do professor devesse envolver ações individualizadas, como tutoria aos alunos, interpretada como suporte para orientação de estudos e construção do projeto de vida e a realização de ações conjuntas, a partir do trabalho integralizado, na criação de disciplinas eletivas junto com outros docentes (SÃO PAULO, 2014a).

Para que haja uma compreensão da complexidade e adaptação dos professores ao Programa, de acordo com João, o PEI estabelece um rodízio de disciplinas para que os docentes possam ampliar os seus conhecimentos sobre todas as áreas que abrangem o Programa. Além da disciplina de Educação Física, João está ministrando aulas de Projeto de Vida e Orientação de Estudos. Na fala do professor, temos:

No primeiro semestre, eu fiz uma parceria com uma professora de História [...] e a nossa disciplina se chamava "Esculturando", que lembra um pouquinho a questão da escultura e do corpo [...]; a gente trabalhou como que o corpo das pessoas foi entendido ao longo da história. Então a gente fez essa parceria entre Educação Física e História para sextos e sétimos anos. Agora no segundo semestre, eu fiz uma eletiva em parceria com o professor de Geografia né?, e a nossa eletiva chama "O Espaço do Jogo", então a gente trabalha questões que acontecem dentro dos ambientes das práticas corporais, pode ser esportes coletivos, das lutas, das danças, né?, o que que 
acontece de relações humanas dentro desse espaço de jogo, que vai além do ganhar e perder [...]. A gente sabe que as relações humanas entre os praticantes, às vezes não são tão estudadas né?, a gente é mais... estuda-se mais mesmo a técnica de um jogo, as estratégias de um jogo, mas não as relações humanas que acontecem né? E quais dessas relações são legais ou não, a gente trabalha as atitudes de fair play também, e como que isso pode ser relacionado com as relações durante a nossa vida na sociedade e quais aspectos do jogo a gente consegue enxergar fora do ambiente de jogo. Nós temos outras disciplinas também "Mundo do Trabalho", a gente tem, é "Protagonismo Juvenil", então são diversas disciplinas que a gente tem dentro do Programa que vão além da Base Nacional Comum. Eu estou somente esse ano com a Educação Física, a Orientação de Estudos para sexto ano, e o Projeto de Vida para os sétimos anos; no primeiro semestre também teve o Nivelamento, nós separamos os alunos por agrupamento com relação à aprendizagem, eu trabalhei com o agrupamento de Língua Portuguesa, mas foi só no primeiro semestre, no segundo semestre nós não tivemos nivelamento (JOÃO).

Todos esses quesitos apresentados, referentes às responsabilidades do professor no PEI, podem ser englobados nesse "trauma de realidade" devido a essa mudança de contexto escolar vivenciada pelo professor. De acordo Reali e Reyes (2009), a profissão docente, no geral, consiste na responsabilidade social e política dentro da escola e da comunidade. O contexto escolar, em diversos momentos, é imprevisível e com isso, o professor deve estar constantemente aprendendo (REALI; REYES, 2009), independentemente se faz parte do PEI ou não.

$\mathrm{Na}$ entrevista foi possível identificar alguns aspectos positivos e negativos, que o professor julga ser importante mencioná-los sobre o PEI.

O primeiro aspecto positivo foi em relação à inserção do aluno na escola. O professor afirma que a maioria dos alunos presentes no Programa sabe que estes momentos como estudantes serão de preparo para a vida, demonstrando interesse pela escola. De acordo com João, a lista de espera para estudar na escola E.E. Maldonado é "gigantesca". Com isso, o aluno inicia no Programa com essa percepção, da escola como formação, contudo, não foi identificada, nesta pesquisa, como esta percepção é criada pelo aluno. Todavia, o professor considera essa percepção como sendo um aspecto positivo para o PEI.

A estrutura do Programa foi mencionada pelo professor na entrevista. João ressalta que a organização da escola E.E. Maldonado é diferente das outras escolas que lecionou e questiona o porquê dessas outras não pertencentes ao PEI, não aderirem a um número maior de coordenadores na escola. $\mathrm{O}$ fato do Programa apresentar um coordenador para cada área de conhecimento, totalizando quatro coordenadores, é considerado pelo professor como um aspecto positivo.

A escola se preocupa em demonstrar e contemplar o futuro dos alunos, a partir de atividades com aspectos contextualizados, com relação à realidade dos estudantes. No PEI, a escola é "[...] alinhada com a realidade do jovem, preparando os alunos para realizar seu Projeto de Vida e ser protagonista de sua formação" (SÃO PAULO, 2012a, p.13). Para João, a presença das disciplinas específicas do PEI aproxima a escola à realidade do aluno, e com isso conseguem explorar alguns conhecimentos que podem ser diferentes dos retratados pela BNCC, e assim, essas disciplinas específicas pretendem atender mais as necessidades dos estudantes do que aquelas apresentadas pelas áreas gerais do conhecimento. Com isso, o professor considera como ponto positivo a visão dos envolvidos no PEI, sobre a escola ser um caminho para ascensão social.

Durante a entrevista, o professor enfatizou a parte diversificada do PEI. Para João, essa parte específica do PEI, que compõe a matriz curricular do Programa, agrega de maneira considerável na educação do aluno. O professor entende como ponto positivo o fato da escola distanciar-se da pedagogia que considera o aluno como um jovem que vem para a escola apenas para receber conhecimentos, e o professor, visto como o único detentor do saber 
incontestável. No PEI, a escola procura evidenciar que cada aluno possui a sua realidade e que seu futuro pode ser planejado, conquistado e construído a partir de conhecimentos, compartilhados e integralizados de maneira sistematizada, no qual os professores atuam além das salas de aulas, como orientadores, para que o aluno consiga alcançar seus objetivos traçados em seu Projeto de Vida.

O aluno deve construir o seu Projeto de Vida, enquanto o professor deve organizar o seu programa de ação. Ele é um "[...] documento a ser elaborado pelos gestores, professor coordenador geral, pelos professores coordenadores de área de conhecimento e pelos professores, com os objetivos, metas e resultados de aprendizagem a serem atingidos pelos seus alunos" (SÃO PAULO, 2014b, p. 2). Ou seja, o professor terá que se preocupar com a sua atuação na escola e com os objetivos que se propôs a realizar no semestre, pois ele será avaliado por tudo isso. Ao final do ano, o professor realizará o seu "[...] balanço individual [...] apontando os resultados alcançados de forma clara e objetiva" (SÃO PAULO, 2012a, p. 52). O programa de ação é considerado como sendo um aspecto positivo para o professor.

Em relação à remuneração, como indicado anteriormente, o Programa prevê em suas diretrizes que o professor deve receber "Gratificação de Dedicação Plena e Integral - GDPI, que corresponde a 75\% do respectivo salário-base" (SÃO PAULO, 2014a, p. 9). De acordo com o professor, ele considera o valor de seu salário "digno" de um professor da Rede Pública, e acredita que esse valor deveria se estender para além das escolas pertencentes ao Programa. Destacamos que o termo "gratificação" se refere a um pagamento adicional não obrigatório, ou seja, esse valor não é incorporado ao salário, mas é uma remuneração que o professor recebe enquanto exerce suas funções no PEI.

[...] sobre a questão da questão salarial acho importante a gente falar também, que não é que nós ganhamos muito dinheiro, nós ganhamos minimamente aqui um salário que é digno do professor e eu gostaria que fosse estendido, né? pra todos professores da Rede Pública também é...eu entendo a nossa escola aqui no E.E. Maldonado é... como um grande avanço na questão profissional, né? pra mim está sendo um grande avanço porque ela me proporciona, né? essa constante formação, essa constante busca em inovar em fazer novas práticas e pra gente se manter aqui você precisa disso (JOÃO).

A fala do professor pode ser compreendida, através dos estudos de Souza e Paixão (2015), que buscam entender e refletir sobre o porquê a docência ser desvalorizada no Brasil. Os autores entendem que na profissão de professor existem além do desprestígio social, várias dificuldades e desafios que acabam consequentemente desvalorizando o salário do professor. Especificamente na Educação Física, surge para o professor, outro desafio, além desses já mencionados, pois a disciplina possui como seu objeto de estudo o movimento humano através das práticas corporais e culturais, essas características podem vir a desvincular o propósito pedagógico da disciplina, provocando interpretações equivocadas por parte de alunos e professores causando empecilhos para o desenvolvimento da área (SOUZA; PAIXÃO, 2015).

O professor concluiu os aspectos positivos com a evidente aproximação da universidade com a escola. Esta aproximação é considerada por Neira (2012) como sendo positiva também, se as pesquisas surgirem a partir das necessidades das escolas e procurar entender qual a perspectiva que os envolvidos estão vivenciando determinado cotidiano escolar, pois como ressalta o autor " [...] um conhecimento mais profundo dos processos vividos pelo professor ao longo do seu percurso profissional possibilitará a proposição de políticas específicas que lhe deem o suporte necessário em diversas instâncias, dentro e fora da escola" (NEIRA, 2012, p. 252).

Foram identificadas as responsabilidades atribuídas aos professores, desde as previstas na BNCC, que abrange todas as escolas brasileiras, até a parte específica do PEI, no qual são 
demonstradas desde uma tutoria aos alunos, apresentando um caráter mais individual, até ministrar aulas com conteúdos diferentes daqueles referentes, especificamente na Educação Física, como no caso do professor João. Com isso, seria interessante ser concedida ao professor, uma formação prévia para iniciar no Programa.

De acordo com João, a Diretoria de Ensino de São Carlos oferece esse curso, porém, no ano de sua inserção essa formação não existiu. O professor não soube dizer o motivo da ausência dessa preparação, mas afirma ter sentido falta dela. Sua adaptação foi através dos outros professores que já lecionavam no Programa antes da sua inserção. Através desse relato podemos dizer que, neste ano, por motivos desconhecidos pelo próprio professor João, a DE não ofereceu uma preparação para os professores que ingressaram em 2019 no PEI.

\begin{abstract}
Nós não tivemos essa formação esse ano né?, então a aprendizagem vem acontecendo na própria escola, com os gestores, com os meus pares, e nas práticas do dia a dia. Então eu senti falta dessa formação inicial por que além das disciplinas diferentes que tem, nós temos a questão também da tutoria né?, cada professor tem por volta de 20 alunos, e você é responsável pela questão da aprendizagem acadêmica desses alunos. Então toda semana eu me encontro uma hora com esses alunos, para ver os cadernos, para fazer uma orientação com relação aos estudos, eu peço fichas de estudos mensais, o que eles estão estudando em casa, eles têm que por no papel e me entregar. Então, assim, o programa ele é muito abrangente, essas são algumas das coisas que eu coloquei, são muitas outras responsabilidades. E eu senti um pouco dessa falta da formação inicial, embora a gestão e meus pares são excelentes com essa questão de inserir o professor novato, acho assim, que quem está aqui acredita mesmo no programa né?, é algo que deu certo, pelo menos na nossa escola, eu posso afirmar hoje que é algo que deu certo, então eles se preocupam em formar quem entra para que o programa continue dando certo assim né? (JOÃO).
\end{abstract}

A falta de uma formação prévia no caso específico do professor teve um impacto negativo em sua inserção. Atrelado a esse efeito foi relatado por João, que o Programa poderia apresentar uma efetividade maior se tivesse mais docentes, pois alega que a sua responsabilidade no Programa é "imensa". O professor concluiu que a quantidade de docentes presentes na E.E. Maldonado é pequena e se tivesse mais professores, a carga sobre cada docente seria distribuída, evitando a sobrecarga e, consequentemente, exerceriam o trabalho com mais qualidade.

Porque a nossa sobrecarga aqui ela é imensa. Se você quer fazer um trabalho certo e bom dentro da Educação Física já tem que ter uma dedicação imensa. Quando você é responsável por várias disciplinas, esse planejamento e essa dedicação tem que ser elevada ai exponencialmente, né? E isso acaba sobrecarregando um pouco. Eu tenho visto alguns colegas, que estão há mais anos aqui bem cansados também [...], por toda essa sobrecarga que tem aí, anual [...] durante as aulas mesmo e a preparação delas também (JO ̃̃O).

Dias (2018), em estudo realizado com 11 professores(as) de uma escola de PEI em Votorantim-SP, indicou que foi possível "[...] constatar que a gratificação salarial e a possibilidade de formar uma jornada de trabalho em uma única unidade têm promovido a adesão e o interesse dos educadores da rede no programa" (p. 14). Por outro lado, de forma crítica, a autora aponta que:

A intensificação e rotinização do trabalho docente têm permanecido ocultas nas escolas do PEI, através de uma faixada de participação na escolha de metodologias e na criação de novas técnicas de ensino e atuação pedagógica. Dessa forma, a ausência de espaço para a construção de reflexões críticas e para a participação 
efetiva dos docentes na elaboração das políticas educacionais paulistas ainda permanece um desafio para a Secretaria de Educação paulista (p. 15).

Entendemos, desta forma, que os resultados apontados por Dias (2018), se assemelham às colocações feitas pelo professor João. A partir do momento que o PEI afirma o compromisso com a educação nas escolas, o Programa é dependente de ações conjuntas de todos os envolvidos para que funcione.

A avaliação $360^{\circ}$ promove a oportunidade de diversos integrantes da escola avaliarem de acordo com suas óticas, de maneira sistematizada, baseados em seus princípios éticos e morais. Logo, o Programa parte do pressuposto de que todos os envolvidos estão aptos a realizar esse processo avaliativo. Com isso, um dos fatores que irá definir o sucesso dessa avaliação é o comportamento adotado pelos integrantes do PEI durante a sua realização.

Foi visto no PEI que o aluno, de maneira estruturada, compartilha com os professores a responsabilidade de avaliar. O primeiro aspecto positivo foi em relação à inserção do aluno na escola. O professor afirma que a maioria dos alunos presentes no Programa sabe que estes momentos como estudante serão de preparo para a vida. No momento de realização da entrevista existia lista de espera para matrículas, o que, de acordo com João, aparentemente representa que os alunos, antes de matricularem, apresentam um perfil de valorização do ambiente escolar.

Lembramos que a escola está localizada na região central da cidade de São Carlos e dispõe dos seguintes elementos de infraestrutura urbana: rede de energia elétrica, rede de saneamento básico, pavimentação das vias, edifícios comerciais e residenciais. O panorama da localização da E.E. Maldonado atrelado à análise do professor sobre o perfil de valorização do aluno em relação à escola, nos induzem a indicar que esses fatores podem estar correlacionados e influenciar os resultados no PEI.

Em situação oposta, existe a desigualdade social que pode interferir no Programa, revelando que o rendimento do PEI pode estar relacionado ao contexto em que está inserido, sendo assim, vale ressaltar que sua implementação se submete ao conjunto dos elementos que integram uma educação de qualidade.

\section{CONSIDERAÇÕES FINAIS}

Ao estipular o objetivo de analisar a inserção profissional de um professor de Educação Física no PEI, percebe-se que a parte diversificada do Programa é considerada boa, pois procura aproximar a escola à realidade do aluno, porém, as atribuições específicas ao professor são excessivas e deveriam ser distribuídas com a contratação de mais professores.

De acordo com a visão do docente de Educação Física entrevistado, os aspectos positivos se sobressaem aos negativos. As responsabilidades atribuídas ao professor foram assimiladas como sendo estímulos desafiadores para que haja a busca por novos conhecimentos e saberes. Com isso, João indicou ter se adaptado ao PEI e almeja a sua expansão para outras escolas públicas estaduais, bem como a necessidade de melhores salários para os(as) professores(as) de um modo geral.

Salientamos que esta é uma visão que retrata os primeiros impactos que o Programa proporcionou ao professor de Educação Física. Como a experiência de atuação de João ainda é inicial no PEI, indicamos a necessidade de estudos com professores de Educação Física que estão há mais tempo no Programa e/ou com o mesmo professor participante desta pesquisa, depois de vários anos de atuação no PEI. Da mesma forma, acreditamos ser adequado analisar outros atores educacionais envolvidos no Programa, como: gestores, docentes, funcionários, discentes e pais/responsáveis pelos alunos. 
Guilherme Augusto da Silva; Mário Lucio de Amorim Filho; Glauco Nunes Souto Ramos

Indicamos, contudo, como de grande valia a realização dessa pesquisa, já que pudemos conhecer melhor o Programa a partir da vivência de um professor de Educação Física, João, sobre a sua inserção no PEI.

\section{REFERÊNCIAS}

AMORIM FILHO, M. L.; RAMOS, G. N. S. Trajetória de vida e construção dos saberes de professoras de educação física. Revista Brasileira de Educação Física e Esporte, v. 24, n. 2, p. 223-38, abr./jun. 2010.

BETTI, M. Educação física e sociologia: novas e velhas questões no contexto brasileiro. In: CARVALHO, Y. M.; RUBIO, Katia (org.). Educação física e ciências humanas. São Paulo: Hucitec, 2001. p.155-169.

BORGES, C. M. F. O professor de educação física e a construção do saber. 2. ed. Campinas: Papirus, 2001.

BRACHT, V. A educação física no ensino fundamental. In: SEMINÁRIO NACIONAL: CURRÍCULO EM MOVIMENTO, 1., 2010, Belo Horizonte. Anais [...]. Belo Horizonte, 2010. p. 1-14 Disponível em: http://portal.mec.gov.br/docman/dezembro-2010-pdf/7170-3-6-educacao-fisica-ensino-fundamental-walterbracht/file. Acesso em: 10 nov. 2020.

BRACHT, V. Educação física \& ciência: cenas de um casamento (in)feliz. Ijuí: Ed. UNIJUÍ, 1999.

BRASIL. Instituto Nacional de Estudos e Pesquisas Educacionais Anísio Teixeira. Relatório do $3^{\mathbf{o}}$ ciclo de monitoramento das metas do Plano Nacional de Educação 2020. Brasília: INEP/MEC, 2020. Disponível em: http://portal.inep.gov.br/informacao-da-publicacao/-/asset_publisher/6JYIsGMAMkW1/document/id/6974122. Acesso em: 10 nov. 2020.

BRASIL. Ministério da Educação. Base Nacional Comum Curricular. Versão final. Terceira versão. Brasília: MEC, 2017.2 Disponível em: http://basenacionalcomum.mec.gov.br/images/BNCC EI EF 110518 versaofinal_site.pdf. Acesso em: 10 nov. 2020.

BRASIL. Lei no 13.005, de 25 de junho de 2014: aprova o Plano Nacional de Educação - PNE. Disponível em: http://www.planalto.gov.br/ccivil_03/_ato2011-2014/2014/lei/113005.htm. Acesso em: 10 nov. 2020.

CERICATO, I. L. Sentidos e significados da docência, segundo uma professora iniciante. Educação \& Realidade, v. 42, n. 2, p.729-746, 23 fev. 2017.

CRUZ, P.; MONTEIRO, L. (org.). Anuário brasileiro da educação básica. São Paulo: Editora Moderna. 2019.

DIAS, V. C. Programa de ensino integral paulista: problematizações sobre o trabalho docente. Educação e Pesquisa, v. 44, p. e180303, 2018.

GOMES, R. A análise de dados em pesquisa qualitativa. In: MINAYO, M. C. S. (org.). Pesquisa social: teoria, método e criatividade. 23. ed. Petrópolis: Vozes, 2004. p. 67-80.

IBGE. Instituto Brasileiro de Geografia e Estatística. Panorama. 2020. Disponível em: https://cidades.ibge.gov.br/brasil/sp/sao-carlos/panorama. Acesso em: 10 nov. 2020.

LÜDKE, M.; ANDRÉ, M. E. D. A. Pesquisa em educação: abordagens qualitativas. São Paulo: EPU, 1986.

NEGRINE, A. Instrumentos de coleta e informações na pesquisa qualitativa. In: MOLINA NETO, V. (org.). A pesquisa qualitativa na educação física: alternativas metodológicas. 3. ed. Porto Alegre: Sulina, 2010. p. 6199.

NEIRA, M. G. Alternativas existem! Análise da produção científica em dois periódicos brasileiros sobre a docência na Educação Física. Movimento, v. 18, n. 1, p. 241-257, jan./mar. 2012.

PACHECO, J. A.; FLORES, M. A. Formação e avaliação de professores. Porto: Porto Editora, 1999. 
PAPI, S. O. G.; MARTINS, P. L. O. As pesquisas sobre professores iniciantes: algumas aproximações. Educação em Revista, v. 26, n. 3, p. 39-56, 2010.

REALI, A. M. M. R.; REYES, C. R. Reflexões sobre o fazer docente. São Carlos: EdUFSCar, 2009.

REALI, A. M. M. R.; TANCREDI, R. M. S. P.; MIZUKAMI, M. G. N. Programa de mentoria online para professores iniciantes: fases de um processo. Cadernos de Pesquisa, v. 40, n. 140, p. 479-506, maio/ago. 2010.

SÃO PAULO. Dados abertos da educação: adesão de escolas Programa de Ensino Integral (PEI). Disponível em: https://dados.educacao.sp.gov.br/node/1088/download. Acesso em: 10 nov. 2020.

SÃO PAULO. Diretoria de Ensino - Região de São Carlos. Retificação Edital de credenciamento 2018 atuação 2019 para o Programa Ensino Integral. 17 dez. 2018. Disponível em: https://desaocarlos.educacao.sp.gov.br/retificacao edital-de-credenciamento-2018-atuacao-2019-para-oprograma-ensino-integral/. Acesso em: 10 nov. 2020.

SÃO PAULO. Tutorial de recursos humanos: diretrizes do Programa Ensino Integral. abr. 2014a. Disponível em: https://www.educacao.sp.gov.br/a2sitebox/arquivos/documentos/734.pdf. Acesso em: 10 nov. 2020.

SÃO PAULO. Informações básicas: Programa Ensino Integral. abr. 2014b. Disponível em: https://www.educacao.sp.gov.br/a2sitebox/arquivos/documentos/727.pdf. Acesso em: 10 nov. 2020.

SÃO PAULO. Diretrizes do Programa Ensino Integral. 2012a. Disponível em: https://www.educacao.sp.gov.br/a2sitebox/arquivos/documentos/342.pdf. Acesso em: 10 nov. 2020.

SÃO PAULO. Lei Complementar no 1.164, de 04 de janeiro de 2012: institui o Regime de dedicação plena e integral - RDPI e a Gratificação de dedicação plena e integral - GDPI aos integrantes do quadro do Magistério em exercício nas escolas estaduais de ensino médio de período integral. 2012b. Disponível em: https://www.al.sp.gov.br/norma/?id=165008. Acesso em: 10 nov. 2020.

SÃO PAULO. Lei Complementar $\mathbf{n}^{\mathbf{0}}$ 1.191, de 28 de dezembro de 2012: dispõe sobre o Programa Ensino Integral em escolas públicas estaduais e altera a Lei Complementar $n^{\circ} 1.164$, de 2012, que instituiu o Regime de dedicação plena e integral - RDPI e a Gratificação de dedicação plena e integral - GDPI aos integrantes do Quadro do Magistério em exercício nas escolas estaduais de ensino médio de período integral. 2012c. Disponível em: $\quad$ https://www.al.sp.gov.br/repositorio/legislacao/lei.complementar/2012/lei.complementar-119128.12.2012.html. Acesso em: 10 nov. 2020.

SILVA, K. A. C. P. C; CRUZ, S. P. S. As pesquisas sobre ciclos de vida profissional docente: revisão da literatura. Formação em Movimento, v. 2, n. 4, p. 439-458, jul./dez. 2020.

SOARES, C. L.; TAFFAREL, C. N. Z.; VARJAL, E.; CASTELLANI FILHO, L.; ESCOBAR, M. O., BRACHT, V. Metodologia do ensino de educação física. São Paulo: Cortez, 1992.

SOUZA, J. A.; PAIXÃO, J. A. A prática do bom professor de Educação Física na perspectiva dos alunos do ensino médio. Revista Brasileira de Estudos Pedagógicos, v. 96, n. 243, p. 399-415, maio/ago. 2015.

Recebido em: 11 nov. 2020.

Aprovado em: 27 nov. 2020. 